\title{
Biochemical and molecular evidences for the antitumor potential of Ginkgo biloba leaves extract in rodents
}

\author{
Hanaa H. Ahmed ${ }^{1 凶}$, Wafaa Gh. Shousha², Hatem A. El-Mezayen², Sayed A. El-Toumy³, \\ Alaa H. Sayed ${ }^{1,4}$ and Aesha R. Ramadan² \\ 'Hormones Department, National Research Centre, Dokki, Giza, Egypt; ${ }^{2}$ Chemistry Department, Faculty of Science, Helwan University, Cairo, \\ Egypt; ${ }^{3}$ Chemistry of Tannins Department, National Research Centre, Dokki, Giza, Egypt; ${ }^{A}$ Applied Medical Sciences Department, Community \\ College in Al-Qurayyat, Al-Jouf University, KSA
}

Hepatocellular carcinoma (HCC) is one of the deadliest primary cancers, with a 5 -year survival rate of $10 \%$ or less. This study was undertaken to elucidate the underlying biochemical and molecular mechanisms in favor of $\mathrm{N}$-nitrosodiethylamine-induced hepatocellular carcinoma. Furthermore, the aim of this work was extended to explore the efficacy of Ginkgo biloba leaves extract in deterioration of HCC in rats. In the current study, HCC group experienced significant downregulation of ING-3 gene expression and upregulation of Foxp-1 gene expression in liver. Treatment of HCC groups with Ginkgo biloba leaves extract resulted in upregulation of ING-3 and downregulation of Foxp-1 gene expression in liver. In addition, there was significant increase in serum alpha-fetoprotein (AFP), carcinoembryonic antigen (CEA) and glypican-3 (GPC-3) levels in HCC group versus the negative control group. In contrast, the groups with HCC subjected to either high or low dose of Ginkgo biloba leaves extract elicited significant reduction $(P<0.05)$ of AFP, CEA and GPC-3 in serum compared to the untreated HCC rats. Besides, histological examination of liver tissue sections of rats in HCC group revealed typical anaplasia. Interestingly, treatment with Ginkgo biloba leaves extract elicited marked improvement in the histological feature of liver tissue in HCC groups. In conclusion, this research indicated that the carcinogenic potency of $\mathrm{N}$ nitrosodiethylamine targeted multiple systems on the cellular and molecular levels. In addition, the results of the current study shed light on the promising anticancer activity of Ginkgo biloba leaves extract in treatment of hepatocellular carcinoma induced chemically in the experimental model through its apoptotic and antiproliferative properties.

Key words: Hepatocellular carcinoma; Ginkgo biloba; AFP; CEA; GPC3; ING-3; Foxp-1; histopathology

Received: 14 October, 2015; revised: 28 June, 2016; accepted: 13 July, 2016; available on-line: 14 October, 2016

\footnotetext{
e-mail: hanaaomr@yahoo.com

Abbreviations: AFP, alpha-fetoprotein; ANOVA, one way analysis of variance; CEA, carcinoembryonic antigen; DNMT1, DNA methyltransferase-1; FADD, Fas-associated death domain; Foxp-1, Forkhead box transcription factor; GPC-3, glypican-3; HCC, Hepatocellular carcinoma; HBV, hepatitis B virus; HCV, hepatitis C virus; ING3, inhibitor of growth-3; NDEA, N-nitrosodiethylamine; SAH, S-adenosyl-L-homocysteine; SAM, S-adenosyl methionine; Skp2, S-phase kinase-associated protein-2; SPSS, statistical Package for the Social Sciences; STAT3, signal transducer and activators of transcription 3 and Tcf, transactivate T cell factor
}

\section{INTRODUCTION}

Hepatocellular carcinoma (HCC), like any other cancer, develops when there is a mutation in the cellular machinery that causes the cell to replicate at a higher rate and results in the cell growth avoiding apoptosis (Sapisochin \& Charco, 2011). Among the primary liver cancers, HCC represents the major histological subtype, accounting for $70 \%$ to $85 \%$ of the total liver cancer burden worldwide (Wang \& Shen, 2013). Globally, it is the fifth most common cancer and the second leading cause of cancer-related death (Zhang et al., 2013). In developing countries, incidence rates are two- to three-folds higher than in developed countries (Harring et al.,2011).

In Egypt, HCC contributes to $14.8 \%$ of all cancer mortality with a higher incidence in males (17.3\%) than in females $(11.5 \%)$. It is the second most frequent cancer type in Egyptian males after bladder cancer and the eighth most frequent in Egyptian females (Aleem et al., 2012). Hospital-based studies from Egypt reported an overall increase in the relative frequency of all liverrelated cancers in Egypt, from approximately $4 \%$ in 1993 to $7.3 \%$ in 2003 (El-Zayadi et al., 2005). This rising incidence may be due to high prevalence of hepatitis $\mathrm{C}$ virus $(\mathrm{HCV})$ and its complications and the fact that people born 20 years ago or earlier in Egypt have not been vaccinated against hepatitis B virus (HBV) (Lehman et al., 2008). The strongest risk factors for HCC include chronic inflammations of the liver and subsequent cirrhosis due to hepatitis $\mathrm{B}$ and hepatitis $\mathrm{C}$ viral infections, alcohol abuse and metabolic liver diseases (diabetes and non-alcoholic fatty liver disease). Moreover, obesity, environmental pollutants, consumption of food contaminated with the fungal toxins such as aflatoxins produced by Aspergillus flavus in food grains as well as nitrosamine consumption are the common risk factors for HCC development (Farazi \& De Pinho, 2006).

$\mathrm{N}$-nitrosodiethylamine (NDEA) is an N-nitroso alkyl compound described as an effective hepatotoxin in the experimental animals, generating toxicity due to frequent administration (Jose et al., 1998). Nutrients containing NDEA include smoked, salted and dried fish, cheese, cured meat, soybeans and alcoholic beverages (Liao et al., 2001). NDEA is mostly metabolized in the liver by the action of cytochrome p450 enzymes, and its reactive metabolites are mainly responsible for its hepatotoxic effects. NDEA is activated to ethyldiazonium ion which alkylates DNA bases to form pro-mutagenic adducts such as O6-ethyldeoxyguanosine and O4 and O6-ethyldeoxythymidine and these bioactive molecules induce oxidative stress and cytotoxicity by damaging biomol- 
ecules such as DNA, lipids and proteins (Verna et al., 1996).

The tumor-suppressor ING3 gene plays a continuous role throughout the cancer advancement and development. The changes of this gene were shown to be involved in tumor transcriptional regulation, apoptosis and cell cycle arrest. Yang and coworkers (2012) demonstrated that the dysregulation of ING3 in HCC occurred at both transcription and translation levels. It was found that ING3 was significantly downregulated in HCC tissues compared with adjacent non-cancerous tissues. The immunohistochemical staining of tissue microarray data indicated a significant reduction of ING3 expression in $57.14 \%$ of HCC cases (64/112). Such downregulation was associated with the tumor differentiation stage and correlated with tumorigenesis, and the advancement of HCC (Lu et al., 2012).

Forkhead box transcription factor (Foxp-1) gene, a member of F box family of ubiquitously expressed transcription factors, plays a critical role in cancer development. The expression of FOXP1 mRNA and protein in hepatic cancer cells is much higher than in normal hepatic cells. The comparison of clinicopathological characteristics and immunohistochemistry showed that the high expression of FOXP1 in HCC was related to large tumor diameter, high serum $\alpha$-fetoprotein levels, and later stage grouping with tumor node metastasis classification. It was shown that high FOXP1 expression correlates with an aggressive malignant phenotype and may constitute a novel prognostic factor for HCC (Zhang et al., 2012).

Natural products are non-toxic extracts or compounds that compared with synthetic equivalents, generally produce less side effects (Genoux et al., 2011). Ginkgo biloba belongs to the botanical family of Ginkgocea, one of the best known examples of a living fossil. The constituents of Ginkgo biloba leaves include high levels of flavonoids (kaempferol and quercetin), terpenoids (ginkgolides and bilobalide) and Biflavonoids (ginkgetin) (Puttalingamma, 2015). Ginkgo biloba leaves extract has powerful anticancer properties through its antioxidant, gene-regulatory and antiangiogenic properties (Sagar et al., 2006). Gink.go biloba leaves extract could regulate cell proliferation and induce apoptosis, therefore, it might have protective effects against hepatocarcinogenesis (Chao \& Chu, 2004).

The current study was designed to elucidate the biochemical and molecular mechanisms of $\mathrm{N}$-nitrosodiethylamine-induced HCC in rats. In addition, our objective was extended to investigate the potency of Ginkgo biloba leaves extract in inhibiting the HCC progression with special concern for its mechanism of action.

\section{MATERIALS AND METHODS}

\section{Materials}

Chemicals and drug. N-nitrosodiethylamine (NDEA) (CAS no. 55-18-5) was purchased from Sigma-Aldrich Chemicals Co. (St Louis, MO, USA). Doxorubicin was supplied from Pharmacia Italia S.P.A. Milan, Italy. All other chemicals used in the present study were of high analytical grade and were purchased locally (Egypt).

Plant materials. Ginkgo biloba leaves were purchased from local market, Cairo, Egypt. The plant was authenticated by Professor Ibrahim El-Garf, Professor of Plant Taxonomy, Department of Botany, Faculty of Science, Cairo University. Voucher Specimens were kept in the museum of the Department of Pharmacognosy, Faculty of Pharmacy, Cairo University, Cairo, Egypt.

Preparation of Ginkgo biloba leaves methanolic extract. Ginkgo biloba leaves methanolic extract was prepared by adding $2000 \mathrm{ml}$ of $70 \%$ methanol to $1 \mathrm{~kg}$ of Ginkgo biloba leaves and leaving the mixtur for 72 hours, then the extract was filtered using filter paper. Then the filtrate was evaporated under reduced pressure at 45$50 \mathrm{C}$ using rotary evaporator to give a dry residue of crude aqueous methanolic extract (4.5\% from dry leaves) (Van Beek, 2002).

Animals and experimental protocol. A total number of 60 adult female albino rats of Wister strain weighing 120-150 g were used in the current study. The rats were obtained from the Animal House Colony of the National Research Centre, Giza, Egypt. The animals were housed in polypropylene cages in an environmentally-controlled clean air room with a temperature of $25 \pm 1^{\circ} \mathrm{C}$, an alternating $12 \mathrm{~h}$ light $/ 12 \mathrm{~h}$ dark cycle, a relative humidity of $60 \pm 5 \%$ and free access to tap water and a standard rodent chow (Wadi El Kabda Co., Cairo, Egypt). The animals were allowed to adapt to these conditions for 2 weeks before the beginning of the experimental protocol. The animal experimental protocol was approved by the Ethical Committee for Medical Research, National Research Centre, Egypt. Following the acclimatization period, the animals were divided into 5 groups (12 rats/ group) as follow: (1): Normal healthy rats received $1 \mathrm{ml} / \mathrm{rat}$ normal saline orally and served as negative control group, (2): Hepatocellular carcinoma (HCC) group consisted of rats with orally administered NDEA (dissolved in $0.9 \%$ normal saline), in a dose of $20 \mathrm{mg} / \mathrm{kg} \mathrm{b} . w t$. five times/week for four weeks and $10 \mathrm{mg} / \mathrm{kg}$ b.wt. for another week (Karimov et al., 2003). HCC tumor model was established after the fifth week of NDEA administration and confirmed by pathological investigation. (3): Doxorubicin-treated group (HCC+Doxo) in which the rats were treated with doxorubicin intraperitoneally (i.p.) as reference drug in dose of $0.72 \mathrm{mg} / \mathrm{rat}$ which is equivalent to the human dose of $20 \mathrm{mg} / \mathrm{m}^{2}$ according to Barnes and Paget (Barnes \& Paget, 1965) once weekly for 9 weeks. (4): Ginkgo biloba (high dose)-treated group (HCC+ Ginkgo biloba $\mathrm{H}$ ) of rats with orally administered $0.675 \mathrm{~g} / \mathrm{kg}$.b.wt/ day of Ginkgo biloba leaves extract five times a week for 9 weeks and (5): Ginkgo biloba (low dose)-treated group (HCC+ Ginkgo biloba L) of rats with orally administered $0.337 \mathrm{~g} / \mathrm{kg}$.b.wt/day of Ginkgo biloba leaves extract five times a week for 9 weeks. The treatment with doxorubicin or Ginkgo biloba leaves extracts was started following the induction of HCC.

Blood sampling. After the completion of the treatment (14 weeks), all animals fasted for 12 hours then the blood samples were collected from the retro-orbital venous plexus under diethyl ether anaesthesia. Blood samples were left to clot and the sera were separated by cooling centrifugation at $1800 \times g$ for $10 \mathrm{~min}$ at $4^{\circ} \mathrm{C}$ and stored immediately at $-20^{\circ} \mathrm{C}$ in clean Eppendorf prior the biochemical analysis.

Liver tissue sampling. After blood collection, the animals were sacrificed by cervical decapitation, dissected and the whole liver of each rat was rapidly excised and thoroughly washed with isotonic saline. Later, whole liver of each rat was divided into two portions; the first portion was fixed in formalin saline $(10 \%)$ for $24 \mathrm{~h}$ for histological examination whereas, the second portion was snap-frozen directly in liquid nitrogen and 
stored at $-80^{\circ} \mathrm{C}$ prior to RNA isolation for gene expression analysis.

\section{Methods}

Biochemical analyses. Serum alpha-fetoprotein (AFP) was determined by ELISA using kit purchased from Glory Science Co., Ltd (USA), according to the manufacturer's instructions provided with AFP assay kit. Serum carcinoembryonic antigen (CEA) was quantified by ELISA using kit purchased from Glory Science Co., Ltd (USA), according to the manufacturer's instructions provided with CEA assay kit. Serum glypican-3 (GPC-3) was detected by ELISA using kit purchased from Glory Science Co., Ltd (USA), according to the manufacturer's instructions provided with GPC-3 assay kit.

Molecular genetic analysis. Isolation of total RNA. Total RNA was isolated from the liver tissue of rats with TRIzol $^{\circledR}$ Reagent (Invitrogen, USA). The isolated RNA was treated with $1 \mathrm{U}$ of RQ1 RNAse-free DNAse (Invitrogen, USA) to digest any DNA residues and then resuspended in DEPC-treated water. The purity of RNA was assessed by 260/280 $\mathrm{nm}$ ratio (between 1.8 and 2.1). Additionally, the integrity was assured by the analysis of $28 \mathrm{~S}$ and $18 \mathrm{~S}$ bands using formaldehyde-containing agarose gel electrophoresis.

Reverse transcription (RT) reaction. The Poly $(\mathrm{A})+$ RNA isolated from the rat liver tissues was reverse transcribed into cDNA in a total volume of $20 \mu \mathrm{l}$ using RevertAidTM First Strand cDNA Synthesis Kit (MBI Fermentas, Germany) according to the manufacturer's instructions provided with the kit.

Semi-quantitative real time-polymerase chain reaction (sqRT-PCR). A Rotor-Gene Q - Qiagen (USA) was used to determine the rats cDNA copy number. The subsequent PCR was performed using a $25 \mu \mathrm{L}$ reaction mixtures containing $12.5 \mu \mathrm{L} 1 \times \mathrm{SYBR}^{\circledR}$ Premix Ex TaqTM (TaKaRa, Biotech. Co. Ltd.), $0.5 \mu \mathrm{L}$ of 0.2 $\mu \mathrm{M}$ forward primer, $0.5 \mu \mathrm{L}$ of $0.2 \mu \mathrm{M}$ reverse primer, $6.5 \mu \mathrm{L}$ distilled water, and $5 \mu \mathrm{L}$ of cDNA template. The cycling conditions were summarized in Table 1. Each experiment included a distilled water control. The semi

Table 1. sqRT-PCR reaction program

\begin{tabular}{lll}
\hline Step 1: (1 cycle) & Temperature & Time \\
\hline $\begin{array}{l}\text { a: Initial denaturation step } \\
\text { Step 2: (30 cycles) }\end{array}$ & $95.0^{\circ} \mathrm{C}$ & $03.00 \mathrm{~min}$ \\
\hline a: denaturation step & $95.0^{\circ} \mathrm{C}$ & $00.15 \mathrm{sec}$ \\
b: annealing step & $55.0^{\circ} \mathrm{C}$ & $00.30 \mathrm{seC}$ \\
c: extension step & $72.0^{\circ} \mathrm{C}$ & $00.30 \mathrm{sec}$ \\
Step 3: (71 cycles) & & \\
\hline a: melting curve analysis & $60.0^{\circ} \mathrm{C}$ & $00.10 \mathrm{sec}$ \\
Then increased about every $0.5^{\circ} \mathrm{C} 10 \mathrm{sec}$ up to $95^{\circ} \mathrm{C}$ & & \\
\hline
\end{tabular}

quantitative values obtained in RT-PCR (sqRT-PCR) for the studied genes were normalized against the expression value of $\beta$-actin gene (house-keeping gene).

Primer sequences were as follows: ING3, F: 5'-AGT GGC AGG AAG AGC AAA AA-3', R: 5'-TCC CAC CAT CTC TCC ATA GG-3', Foxp-1, F: 5'-CAG GCA GAT CCC CTA TGC AA-3', R: 5'-GGA CAG AGG GCC T'TC AGC 'T'T-3' (Shu et al., 2007) and $\beta$-actin, F: 5'-CCC CAT CGA GCA CGG TAT TG-3', R: 5'-ATG GCG GGG GTG TTG AAG GTC-3' (Eshak et al., 2010). At the end of each sqRT-PCR, a melting curve analysis was performed at $95.0^{\circ} \mathrm{C}$ to check the quality of the used primers.
Calculation of gene expression. The amplification efficiency (Ef) was calculated from the slope of the standard curve using the following formula: (Bio-Rad Laboratories Inc, 2006).

Ef $=10^{-1 / \text { slope }}$

Efficiency $(\%)=(E f-1) \times 100$

The relative quantification of the target gene compared to the reference gene was determined by using the $\Delta$ CT method if E for the target (ING3 and Foxp-1) and the reference primers ( $\hat{a}$-actin) are the same:

Ratio (reference/ target gene) $=\mathrm{Ef}_{\mathrm{T}}$ (reference) $-\mathrm{C}_{\mathrm{T}}$ (target)

Histological examination. After the fixation of the second portion of the liver tissue in formal saline $(10 \%)$ for 24 hours, The tissue were subjected to dehydration using series of alcohols (methyl, ethyl and absolute ethyl alcohol) followed by embedding in paraffin wax at $56^{\circ} \mathrm{C}$. After that, the wax tissue blocks were sectioned by sliding microtome and then prepared for the histological slide examination under the light electric microscope (Olympus Cx21 with attached digital camera) after staining with hematoxylin and eosin stain (Drury \& Wallington, 1980).

Statistical analysis. In the present study, the results were expressed as Mean \pm S.E. of the mean. Data were analyzed with one way analysis of variance (ANOVA) using the Statistical Package for the Social Sciences (SPSS) program, version 14 followed by least significant difference (LSD) to compare significance between groups (Armitage and Berry, 1987). Difference was considered significant when $P$ value was $<0.05$.

\section{RESULTS}

\section{Biochemical analyses}

The results in Table (2) show that there was significant increase $(P<0.05)$ in serum AFP, CEA and GPC-3 levels in HCC group versus the negative control group (Ahmed et al., 2015). Insignificant decrease $(P>0.05)$ in serum AFP level was recorded in HCC rats treated with doxorubicin as compared to untreated HCC rats. Significant decreases $(P<0.05)$ in serum CEA and GPC-3 levels were detected in HCC rats treated with doxorubicin in comparison to the untreated HCC rats (Ahmed et al., 2015). Similarly, the groups with HCC treated with either high $(0.675$ g/kg.b.wt.) or low $(0.337$ g/kg.b.wt.) dose of Gink.go biloba leaves extract elicited significant reduction $(P<0.05)$ in serum AFP, CEA and GPC-3 compared to the untreated HCC rats (Table 2).

The data in Table 2 revealed that the treatment of HCC rats with high dose of Ginkgo biloba leaves extract induced significant reduction $(P<0.05)$ in serum AFP and GPC-3 levels compared to doxorubicin-treated group. Meanwhile, treatment of HCC rats with high dose of Ginkgo biloba leaves extract produced insignificant reduction $(P>0.05)$ in serum CEA level in comparison with doxorubicin-treated group (Table 2). Treatment of HCC rats with low dose of Ginkgo biloba leaves extract elicited insignificant reduction $(P>0.05)$ in serum AFP and CEA levels, and significant depletion $(P<0.05)$ in serum GPC- 
Table 2. Effect of treatment with Ginkgo biloba leaves extract and doxorubicin on serum AFP, CEA and GPC-3 levels in hepatocellular carcinoma rat model

\begin{tabular}{llll}
\hline $\begin{array}{l}\text { Parameters } \\
\text { Groups }\end{array}$ & $\begin{array}{l}\text { AFP } \\
(\mathrm{ng} / \mathrm{mL})\end{array}$ & $\begin{array}{l}\text { CEA } \\
(\mathrm{ng} / \mathrm{mL})\end{array}$ & $\begin{array}{l}\text { GPC-3 } \\
(\mathrm{pg} / \mathrm{mL})\end{array}$ \\
\hline Negative control & $19.1 \pm 1.5$ & $0.12 \pm 0.01$ & $9.4 \pm 0.2$ \\
\hline HCC & $40.1 \pm 2.9^{\mathrm{a}}$ & $0.6 \pm 0.06^{\mathrm{a}}$ & $28.6 \pm 0.6^{\mathrm{a}}$ \\
\hdashline HCC + Doxo & $36.9 \pm 1.8$ & $0.45 \pm 0.04^{\mathrm{b}}$ & $22.4 \pm 0.3^{\mathrm{b}}$ \\
\hline HCC + Ginkgo biloba H & $28.5 \pm 2.0^{\mathrm{bc}}$ & $0.39 \pm 0.04^{\mathrm{b}}$ & $17.4 \pm 0.4^{\mathrm{bc}}$ \\
\hline HCC + Ginkgo biloba L & $32.5 \pm 2.3^{\mathrm{b}}$ & $0.41 \pm 0.03^{\mathrm{b}}$ & $19.8 \pm 0.3^{\mathrm{bc}}$ \\
\hline
\end{tabular}

All data are expressed as means \pm standard error S.E. for 8 animals/group. HCC: hepatocellular carcinoma. Doxo, Doxorubicin. Ginkgo biloba H: Ginkgo biloba leaves extract (high dose $0.675 \mathrm{~g} / \mathrm{kg}$.b.wt). Ginkgo biloba L: Ginkgo biloba leaves extract (low dose $0.337 \mathrm{~g} / \mathrm{kg}$. b.wt). aSignificant change at $P<0.05$ in comparison


with HCC group. cSignificant change at $P<0.05$ in comparison with HCC + Doxo group.

3 level in comparison with doxorubicin-treated group (Table 2).

\section{Molecular genetics analysis}

As illustrated in Fig. 1, the current results revealed that there was a significant downregulation $(P<0.05)$ of the expression level of ING3 gene in the liver tissue of HCC rats compared to the negative control group (Ahmed et al., 2015). Significant upregulation $(P<0.05)$ of the expression level of ING3 gene was detected in liver tissue of HCC rats and treated with doxorubicin versus the untreated HCC rats (Fig. 1) (Ahmed et al., 2015). Similarly, the treatment of HCC rats with Ginkgo biloba leaves extract in either high $(0.675 \mathrm{~g} / \mathrm{kg}$. b. wt. $)$ or low $(0.337 \mathrm{~g} / \mathrm{kg}$. b. wt. $)$ dose elicited significant upregulation $(P<0.05)$ of the expression level of ING3 gene in the liver tissue as compared to the untreated HCC rats.

In comparison to doxorubicin-treated group, treatment of HCC rats with high dose of Ginkgo biloba leaves extract resulted in significant change $(P<0.05)$ in the expression level of ING3 gene in the liver tissue, whereas, insignificant upregulation $(P>0.05)$ of the expression level of ING3 gene in the liver tissue was detected in HCC rats treated with low dose of Ginkgo biloba leaves

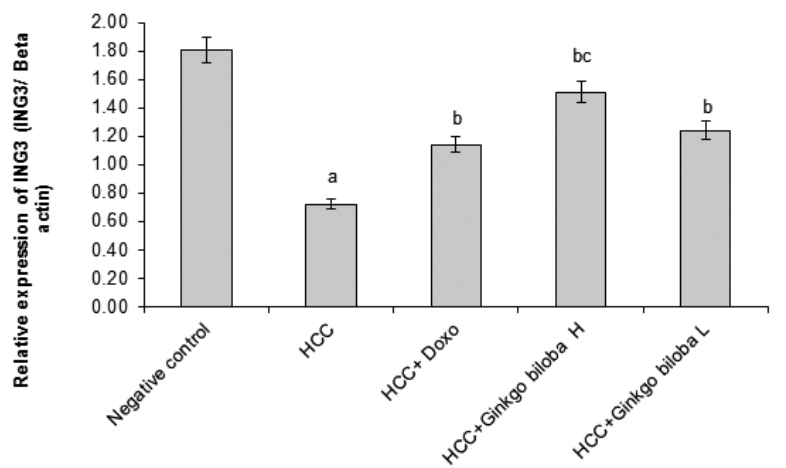

Figure 1. Effect of treatment with Ginkgo biloba leaves extract and doxorubicin on hepatic ING3 gene expression level in hepatocellular carcinoma rat model.

HCC: hepatocellular carcinoma. Doxo, Doxorubicin. Ginkgo biloba $\mathrm{H}$ : Ginkgo biloba leaves extract (high dose $0.675 \mathrm{~g} / \mathrm{kg}$.b.wt). Ginkgo biloba L: Ginkgo biloba leaves extract (low dose $0.337 \mathrm{~g} / \mathrm{kg}$.b.wt). aSignificant change at $P<0.05$ in comparison with the negative control group. bSignificant change at $P<0.05$ in comparison with HCC group. cSignificant change at $P<0.05$ in comparison with HCC + Doxo group. extract as compared to doxorubicin-treated group (Fig. 1).

As represented in Fig. 2, the present results showed that there was significant upregulation $(P<0.05)$ of the expression level of Foxp-1 gene in the liver tissue of HCC rats with respect to the negative control group (Ahmed et al., 2015). Treatment of HCC rats with doxorubicin elicited significant downregulation $(P<0.05)$ of the gene expression level of Foxp-1 in the liver tissue compared to the untreated HCC rats (Fig. 2) (Ahmed et al., 2015). In the same manner, the treatment of HCC rats with either high or low dose of Ginkgo biloba leaves extract induced significant downregulation $(P<0.05)$ of the expression level of Foxp-1 gene in the liver tissue in comparison with the untreated HCC rats.

In comparison with doxorubicin-treated group, the treatment of HCC rats with high dose of Ginkgo biloba leaves extract resulted in significant downregulation $(P<0.05)$ of the expression level of Foxp-1 gene in the liver tissue. On the other hand, insignificant downregulation $(P>0.05)$ of the expression level of Foxp-1 gene in the liver tissue was recorded in HCC rats treated with low dose of Ginkgo biloba leaves extract as compared to doxorubicin-treated group (Fig. 2).

\section{Histological examination}

Histological examination of liver tissue section of rat in the negative control group stained with hematoxylin and eosin $(\mathrm{H} \& \mathrm{E})$ showed normal histological structure of the central vein and the surrounding hepatocytes and no histopathological alteration was observed (Fig. 3a) (Ahmed et al., 2015). On the contrary, microscopic investigation of liver tissue section of rat in HCC group showed anaplastic hepatocytes activities indicated by polarity, pleomorphism and hyperchromatic nuclei and the ratio between the nucleus and cytoplasm was 1:1 which is associated with acinar glandular structure formation (Fig. 3b) (Ahmed et al., 2015). Photomicrograph of liver tissue section of HCC and doxorubicin-treated rat showed thickening and fibrosis with inflammatory cell infiltration and dilated blood capillaries in liver capsules. Also, many liver cells showed karomegaly and pyknotic nuclei

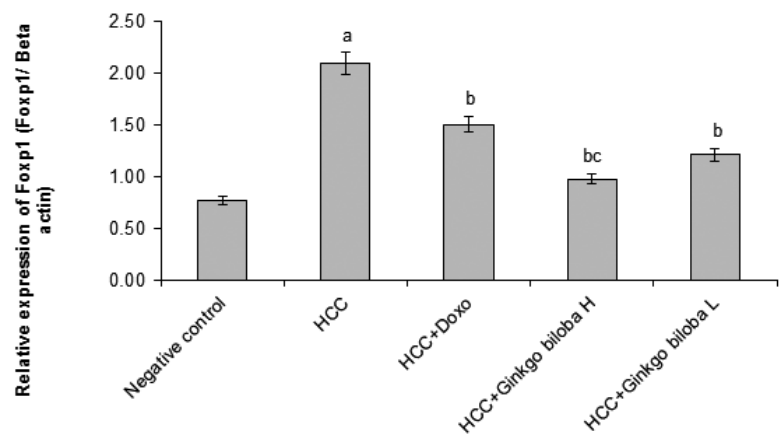

Figure 2. Effect of treatment with Ginkgo biloba leaves extract and doxorubicin on hepatic Foxp-1 gene expression level in hepatocellular carcinoma rat model.

HCC: hepatocellular carcinoma. Doxo, Doxorubicin. Ginkgo biloba $\mathrm{H}$ : Ginkgo biloba leaves extract (high dose $0.675 \mathrm{~g} / \mathrm{kg} . \mathrm{b} . w \mathrm{t}$ ). Ginkgo biloba L: Ginkgo biloba leaves extract (low dose $0.337 \mathrm{~g} / \mathrm{kg} . \mathrm{b} . w \mathrm{wt}$ ). aSignificant change at $P<0.05$ in comparison with the negative control group. bSignificant change at $P<0.05$ in comparison with HCC group. cSignificant change at $P<0.05$ in comparison with HCC + Doxo group. 

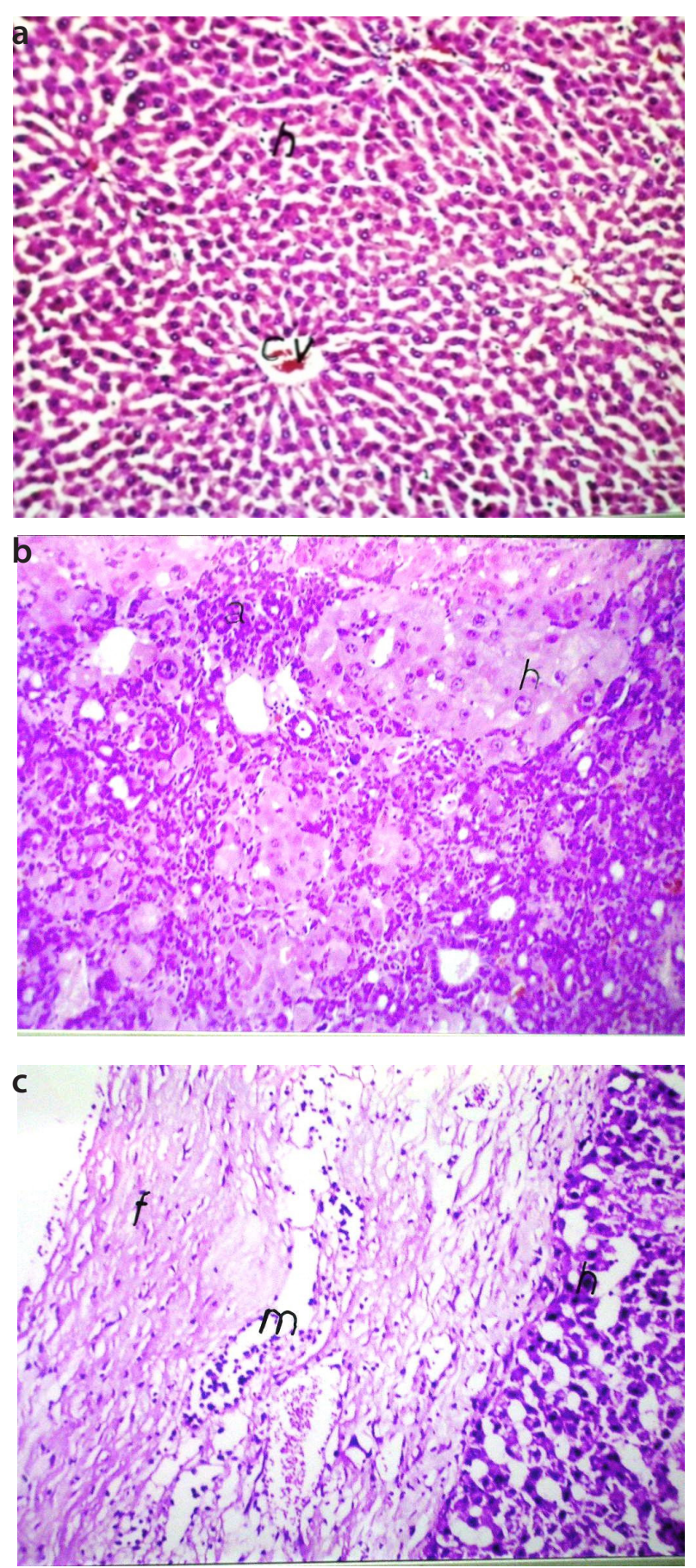

(Fig. 3c) (Ahmed et al., 2015). Photomicrograph of liver tissue section of rat with HCC and the one treated with high dose of Ginkgo biloba leaves extract showed regenerative reaction with inflammatory cells infiltration and dividing the degenerated and necrosed hepatic parenchyma into nodules (Fig. 3d). Photomicrograph of liver tissue section of rat with HCC and the one treated with low dose of Ginkgo biloba leaves extract showed little fibroblastic cells proliferation with inflammatory cells infiltrating in between the degenerated hepatocytes (Fig. 3e).

\section{DISCUSSION}

Chemical induction of HCC with special carcinogens such as $\mathrm{N}$-nitrosodiethylamine (NDEA) is a model close
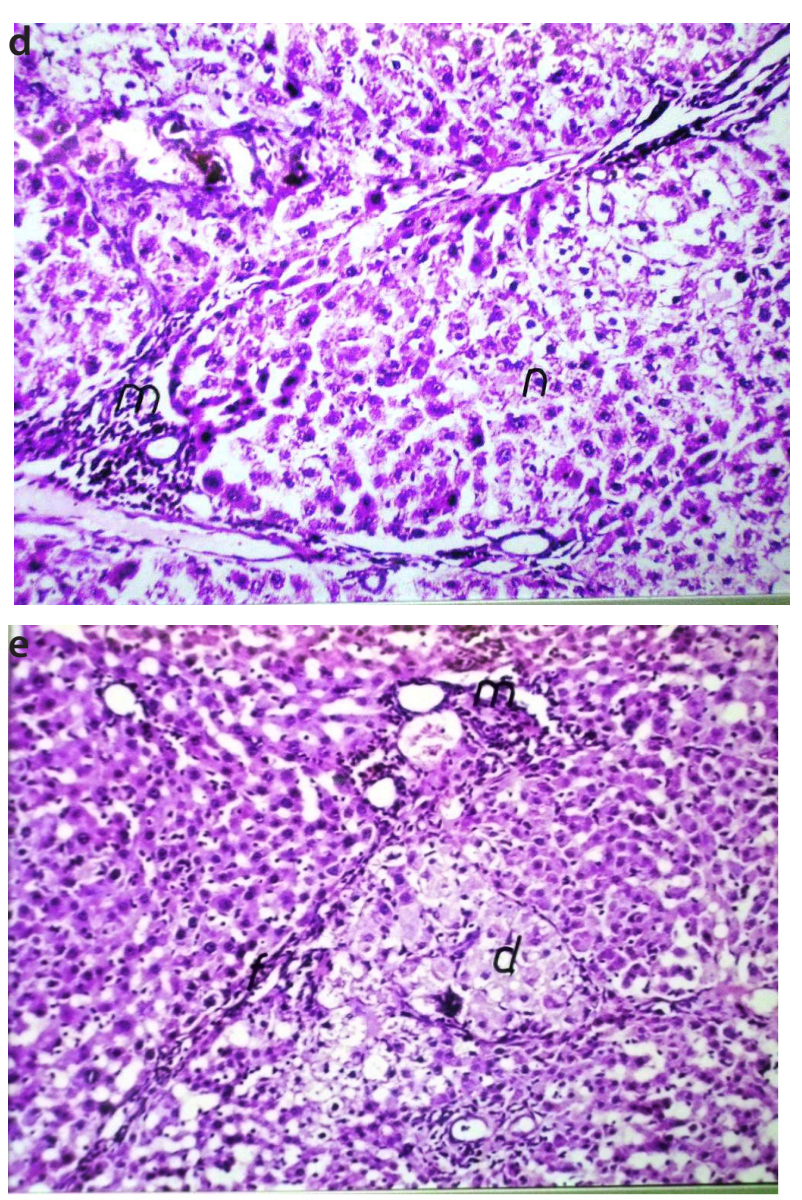

Figure 3. Photomicrograph of the liver tissue sections of rats in (a) The negative control group (H\&E x 40), (b) HCC group (H\&E X 40), (c) HCC group treated with doxorubicin (H\&E X 40), (d) HCC group treated with high dose of Ginkgo biloba leaves extract (H\&E x 40), (e) HCC group treated with low dose of Ginkgo biloba leaves extract (H\&E x 16). Hepatocytes (h); central vein (CV); anaplastic cancer hepatocytes $(\mathbf{C})$; inflammatory cell infiltration $(\mathbf{m})$; fibroblastic cells (f); necrosed hepatic parenchyma (n), degenerated hepatocytes (d)

to human disease. It is widely accepted that metabolic activation of nitrosamines by cytochrome P450 enzymes to reactive electrophiles is required for their cytotoxic, mutagenic and carcinogenic activity. Because of its relatively simple metabolic pathway and potent carcinogenicity, NDEA has been used as an effective experimental model in the field of carcinogenesis and chemoprevention (Ramakrishnan et al., 2009).

The present data revealed that serum AFP level in rats with HCC was significantly elevated. This finding comes in line with other studies that reported that NDEA injection in rats caused significant increase in AFP level in serum (Sadiknah et al., 2008; Sivaramakrishnan et al., 2008) and the gene expression in the liver tissue (Lazarevich, 2000). Zhou et al. (2006) demonstrated that the high serum concentration of AFP in HCC patients might 
be due to the tumor excretion of this protein. Furthermore, some clinical research indicated that the high percentage of AFP is closely related to poor differentiation and biologically malignant characteristics especially portal vein invasion of HCC (Oka et al., 2001). The possible explanations for the reinitiation of AFP synthesis by neoplastic hepatocytes include either increased transcription of AFP gene or post-translational modification affecting AFP production. In rats exposed to chemical carcinogens or those with HCC, AFP production is roughly proportional to the amount of transplantable mRNA present (Motalleb et al., 2008). Steady state AFP transcription may begin prior to the development of histologically or symptomatic hepatocellular carcinoma (Premalatha \& Sachdanandam, 1999).

In view of the present data, serum CEA level in rats with HCC showed significant increase. The elevation in serum CEA levels upon NDEA administration was presumably associated with production rates of tumor, its location, stage, size, differentiation and vascularity (Zimmer \& Thomas, 2001). Macnab and coworkers (1978) demonstrated that the tumor could cause a release of CEA from damaged liver cells adjacent to it. Other studies revealed that CEA is normally removed from circulating plasma by the liver (Thomas \& Hems, 1975). Thus, the increased serum levels of CEA might therefore result from impaired hepatic uptake of CEA or CEA-like glycoproteins.

The efficacy of Ginkgo biloba extract in decreasing the serum levels of AFP and CEA might be explained by its antioxidant properties (Marcocci et al., 1994). The expression of Bcl-xL, Bcl-xS, and Bax could be differently regulated by quercetin, suggesting that the balance in the expression of these proteins might be involved in the control of the apoptotic process. Quercetin decreased the Bcl-xL:Bcl-xS ratio. Herrera and coworkers (2001) proposed that $\mathrm{Bcl}-\mathrm{xL}$ is a caspase substrate. Quercetin also increased Bax translocation from the cytosol to the mitochondrial membrane, an event that promotes apoptotic death. Quercetin inhibited the growth of tumor cells (Middleton et al., 2000).

The decline in serum level of GPC-3 after treatment with Ginkgo biloba leaves extract might be attributed to the inhibitory effect exerted by quercetin towards Beta -catenin/transactivate $\mathrm{T}$ cell factor (Tcf) signaling pathway (Park et al., 2005) and consequently towards c-myc gene as the Beta-catenin/Tcf signaling pathway activates c-myc gene (He et al., 1998) which is a key regulator of GPC3 gene. Thus, the inactivation of $\mathrm{c}-\mathrm{myc}$ gene might lead to the observed depletion in serum GPC-3 level.

The current results revealed that NDEA administration led to significant increase in serum glypican-3 (GPC3) level. Glypican-3 is a heparan sulfate proteoglycan that has an important role in cell growth and differentiation, and its function in carcinogenesis is tissue-dependent (Li et al., 2012a). Moreover, the expression of GPC-3, its receptor, and other growth factors coordinates signal transduction pathways that regulate cellular morphology and a variety of cellular behaviors. GPC-3 is differentially expressed during the invasive growth of liver cancer, so its expression might be involved in the initiation and development of liver cancer (Filmus \& Capurro, 2008). Capurro and coworkers (2003) recorded overexpression of GPC-3 mRNA and protein in both serum and tissues of early-stage HCC. Also, Capurro and coworkers (2005) stated that GPC-3 could enhance the growth of HCC cells by stimulating the Wnt pathway through facilitating the interaction between the Wnts and their signaling receptors. Chan and coworkers (2004) suggested that the upregulation of GPC-3 in some HCC tumors might be attributed to c-Myc gene amplification as it was demonstrated that c-Myc transcriptionally regulates GPC-3 expression by direct interaction with the GPC-3 promoter. Together, these data indicate that the transcription factor c-Myc is a novel regulator of GPC-3 gene and may accelerate the proliferation of liver cancer cells at least in part by upregulating the GPC-3 pathway. Moreover, the exogenous overexpression of c-Myc increased the endogenous mRNA and protein levels of GPC-3 (Li et al., 2012a). In accordance with our results, Suzuki and coworkers (2010) indicated that circulating levels of GPC-3 protein were significantly elevated in patient with HCC and the expression of mRNAs for GPC-3 was markedly elevated in the liver carcinoma tissues. Therefore, GPC-3 showed potential as a tumor biomarker for HCC.

Signal transducer and activators of transcription 3 (STAT3) are involved in oncogenesis through the upregulation of genes encoding apoptosis inhibitors (Bcl-xL, Mcl-1 and survivin), cell-cycle regulators (cyclin D1 and $\mathrm{c}-\mathrm{Myc}$ (DNA binding protein involved in the regulation of nucleic acid metabolism and the response to growth factor)), and inducers of angiogenesis (vascular endothelial growth factor). It was found that STAT3 has an indirect role in GPC-3 expression via upregulation of cmyc; and the poor control of the pathway mediated by STAT3 plays a role in GPC-3 overexpression (Suzuki et al., 2010). Therefore, STAT3 recently drew attention as a novel target for cancer therapy (Fuke et al., 2007).

The current data revealed that the treatment with Dox in HCC rats resulted in marked decrease in AFP, CEA and GPC-3 serum levels. This finding could be attributed to the powerful apoptotic property of Dox. Dox induces apoptosis via $\mathrm{p} 53 /$ Fas/Caspase- 8 system (Friesen et al., 1999). This drug stimulates transcriptional activity of the proapoptotic molecule p53, that triggers expression of the death ligand (Fas L) leading to activation of the Fas receptor. The latter binds, via its cytosolic domain, to adapter proteins like the Fas-associated death domain (FADD) and the apoptosis initiator, caspase- 8 (Cohen, 1997). Activated caspase- 8 cleaves Bid (Kim et al., 2000), producing truncated Bid, which interacts with mitochondria to cause the release of cytochrome $c$. The latter activates caspase-9, conveying apoptotic signals to the nucleus through downstream targets such as caspase-3 and endonucleases, eventually triggering DNA fragmentation and apoptosis (Cohen, 1997).

The results of the current study showed that the expression of inhibitor of growth-3 (ING3) gene in liver tissues of NDEA treated rats was significantly downregulated. It was revealed that ING3 is degraded by Sphase kinase-associated protein-2 (Skp2) mediated ubiquitin proteasome system (Chen et al., 2010). In addition, there was a correlation between the downregulation of ING3 protein and tumor grades as it was shown that the low expression of ING3 protein is correlated with more aggressive behavior of the tumor (Yang et al., 2012). Furthermore, the lower expression of ING3 is also associated with elevated AFP serum levels (Caruso \& Valentini, 1999). It has been reported that $\mathrm{p} 53$ negatively regulated AFP gene expression through alteration of chromatin structure at the core promoter (Ogdene et al., 2001). Studies of Nagashima and coworkers (2003) and Luo and coworkers (2009) demonstrated that ING3 gene regulated $\mathrm{p} 53$. Thus, it is possible to postulate that ING3 could regulate the AFP gene through modifying p53 function. ING3 was shown to modulate p53-mediated transcription, cell cycle control and apoptosis. Thus, ING3 cooperates with $\mathrm{p} 53$ to regulate apoptosis death 
receptor/extrinsic apoptotic pathways (Nagashima et al., 2003). In addition, ING3 was found to upregulate Fas expression at both mRNA and protein levels (Wang \& Li, 2006).

Treatment of HCC rats with Ginkgo biloba leaves extract resulted in significant upregulation in the expression level of liver ING3 gene. Russo and coworkers (2012) reported that quercetin can be efficient in treating cancer by inducing cell death or cell cycle arrest preferentially in cancer cells than in their normal counterparts through a process involving the down-regulation of selective oncogenes, or the up-regulation of tumor suppressor genes (p53, p21), which, in turn, enhance selective pathways leading to the elimination of cancer cells. Quercetin induced apoptosis and cell cycle arrest in HepG2 cells (Tanigawa et al., 2008). Subsequently, quercetin induced p53 activation resulting in increase of p21 and suppression of cyclin D1 expression in favor of cell cycle arrest as well as in increase of $\mathrm{Bax} / \mathrm{Bcl}-2$ ratio in favor of apoptosis (Tanigawa et al., 2008). Also, Chang and coworkers (2006) showed that quercetin-induced cell cycle arrest of HA22T/VGH hepatocarcinogenic cells was due to production of reactive oxygen species.

The present findings revealed that the treatment with Dox in HCC rats caused remarkable upregulation of the expression of ING3 gene in the liver tissue. Deficiency of Fas expression is one of the mechanisms involved in the immune evasion by tumors. Several antitumor drugs, such as Dox causes apoptosis via Fas-mediated activation of caspase- 8 in vitro (Nakamura et al., 2000). However, the significance of Fas expression in vivo is still unclear. Dox was found to be able to induce activation of caspase-8. The role of caspase- 8 appeared to be restricted to apoptosis mediated by death receptors, such as CD95, TNF-R1, and the TRAIL receptors. But, it could be postulated that Dox induces apoptosis through molecular expression of ING3 gene and in turn activation of caspase-8 (Pan et al., 1997).

In the present study, NDEA administration resulted in overexpression of liver forkhead box transcription factor (Foxp-1) gene in rats. Foxp-1 is distinctive as it can act as an oncogene and tumor suppressor depending upon the tissue type (Koon et al., 2007). Significant upregulation of Foxp-1 protein in human primary HCC suggests its potential role in hepatic tumorigenesis (Datta et al., 2008). Foxp-1 was identified as a potential target of miR-1 and the upregulation of miR-1 target Foxp-1 in hepatocellular carcinomas. This further explains the growth regulatory functions of miR-1 in the liver and probably in other tissues by predisposing these tissues to neoplastic transformation due to loss of miR-1. Recently, several studies showed the deregulation of miR-1 in many types of tumor, such as hepatocellular ( $\mathrm{Li}$ et al., 2012b) and renal (Kawakami et al., 2012) cancer. Numerous observations indicated an epigenetic deregulation of miRNAs expression in different tumors, including HCC. MiR-1 downregulation in human HCC is associated with promoter methylation (Datta et al., 2008). Treatment of primary HCC cultures with the hypomethylating agent caused miR-1 reexpression, which in turn led to downregulation of miR-1 oncogenic targets, including Foxp-1 which was overexpressed in HCCs, causing inhibition of cell cycle progression and cell survival (Datta et al., 2008). As miR-1 has specific targets including Foxp-1 that have roles in tumor formation, miR-1's ability to reduce the expression of many tumor promoting genes could have a global influence on the suppression of tumor development (Datta et al., 2008; Reid et al., 2012).
Treatment of HCC rats with Ginkgo biloba leaves extract resulted in significant downregulation in the expression of liver Foxp-1 gene level. Certain polyphenols such as bioflavonoids (quercetin) exert a profound inhibitory effect on DNA methylation and DNA methyltransferase-1 (DNMT1) activities (Yang et al., 2008). Quercetin may indirectly inhibit DNMTs and thus DNA methylation, by changing S-adenosyl methionine (SAM) and S-adenosyl-L-homocysteine (SAH) concentrations inside the cell (Lee et al., 2005).

The current results showed that the treatment with Dox in HCC rats resulted in observable downregulation in Foxp-1 gene expression in the liver tissue. Suggesting that DNA methyltransferase-1 (DNMT1) is one of the targets for Dox-induced apoptosis in cancer cells, it was proposed that the expression levels of DNMT1 in tumor cells might be important criteria that should be taken into account to evaluate the selective cytotoxicity of the drug (Pratt et al., 1994) and to determine the optimal dose regimen. Therefore, the interaction between DNMT1 and Dox might be represented as alternative mechanism for induction of apoptosis in cancer cell by Dox (Yokochi \& Robertson, 2004).

Photomicrographs of liver tissue sections of rats in NDEA group (HCC group) showed anaplastic activity of hepatocytes characterized by polarity, pleomorphism and hyperchromachtic nuclei. In addition, the ratio between the nucleus and cytoplasm was 1:1 with the presence of acinar glandular structure formation. Scherer and Emmelot (1975) stated that in NDEA administered rats, carcinomas are preceded by the development of socalled altered foci and hyperplastic nodules. Also, Burr and coworkers (1996) reported that there was necroinflammation with perivenular inflammatory cells and macrophages in the liver tissue after NDEA administration. Gupta and coworkers (2010) found that NDEA administration caused vacuole formation, loss of normal hepatocyte architecture and presence of pycnotic nuclei. These outcomes might be cause by NDEA being metabolized in the liver and the reactive generated metabolites are known to damage hepatocytes. NDEA is an N-nitroso alkyl compound described as an effective hepatotoxin in experimental animals, causing toxicity after frequent administration (Jose et al., 1998).

The microscopic investigation of liver tissue section of rats with HCC and treated with high dose of Ginkgo biloba leaves extract showed congestion in the central veins while the bile ducts showed proliferation and cystic dilatation with polyps formation. In addition, regenerative reaction with inflammatory cells infiltration dividing the degenerated and necrosed hepatic parenchyma into nodules was observed. These beneficial effects of Ginkgo biloba leaves extract could be partially explained by its antioxidant properties and by inhibition of CYP2E1 that metabolizes NDEA in the liver (Verna et al., 1996). However, regarding the histopathological alterations due to treating HCC bearing rats with low dose of Ginkgo biloba leaves extract, the microscopic investigation of liver tissue sections showed proliferating cystic bile ducts associated with regenerative reactive tissue dividing in the degenerated parenchyma into nodules. Nuclear mitotic activity was noticed in few hepatocytes. In addition, few fibroblastic cells proliferation with inflammatory cells infiltration in between the degenerated hepatocytes was observed.

Histological investigation of liver tissue sections of rats with HCC showed inflammatory cells forming granulomatous lesions and periportal fibrosis after Dox administration. Dox has been shown to induce accumula- 
tion of inflammatory cells (Saad et al., 2001). Moreover, it was reported that Dox was able to cause accumulation of collagen fibers mainly in the portal area, manifested as an early sign of fibrosis (El-Sayyad et al., 2009). Furthermore, microscopic examination of liver tissue sections of rats with HCC and treated with Dox revealed that many hepatocytes showed karyomegaly and pyknotic nuclei indicating apoptosis. Apoptosis is a common feature of hepatotoxicity induced by many anti-carcinogenic drugs. It may precede necrosis or it may occur concurrently with necrosis (Faber, 1994). The influence of Dox on hepatocellular carcinoma comes from its interference with the synthesis of macromolecules, DNA crosslinking and covalent DNA binding, inhibition of topoisomerase II, arresting of tumor cell cycle progression in G2 phase, induction of apoptosis and generation of reactive oxygen radicals (Lubgan et al., 2006).

In summary, hepatocellular carcinoma rat model induced by NDEA represents a well established model for this disease. This was evidenced by significant elevation in serum AFP, CEA and GPC-3 levels, downregulation of ING-3 and overexpression of FOXP-1 genes in liver tissue, in addition to typical anaplasia illustrated by histopathological investigation. The treatment with Ginkgo biloba leaf extracts elicited significant reduction in serum tumor markers and downregulation of oncogene besides upregulation of tumor suppressor gene in liver tissue. Furthermore, Ginkgo biloba leaf extracts restrain the anaplastic features of HCC.

\section{CONCLUSION}

The results of the present study shed light on the underlying biochemical and molecular mechanisms by which $\mathrm{N}$-nitrosodiethylamine could induce hepatocellular carcinoma. Moreover, the present research provided experimental evidences about the potent anticancer activity of Ginkgo biloba leaves methanolic extract in regression of hepatocellular carcinoma in rats.

\section{REFERENCES}

Ahmed HH, Shousha W Gh ,El-Mezayen HA, El-Toumy SA, Ramadan AR (2015) Updates on the biochemical and molecular mechanisms of $\mathrm{N}$-nitrosodiethylamine induced hepatocellular carcinoma: Promising therapeutic role of Punica granatum peel Extract. Int J Pharm Sci Rev Res 32: 121-144

Aleem E, Elshayeb A, Elhabachi N, Mansour AR, Gowily A, Hela A (2012) Serum IGFBP-3 is a more effective predictor than IGF1 and IGF-2 for the development of hepatocellular carcinoma in patients with chronic HCV infection. Oncol Lett 3: 704-712. doi: 10.3892/ol.2011.54

Armitage P, Berry G (1987) Comparison of several groups. In Statistical method in medical research, 2nd edn. pp 86-213. Oxford, Block well significant publication

Barnes JM, Paget GE (1965) Mechanisms of toxic action. Prog Med Chem 4: 18-38

Bio-Rad Laboratories Inc (2006) Real-time PCR applications guide. Bulletin 5279: 101

Burr AW, Hillan KJ, Mclaughlin KE, Ferrier R, Chapman C, Mathew J, Burt AD (1996) Hepatocyte growth factor levels in liver and serum increase during chemical hepatocarcinogenesis. Hepatol 24: 1282-1287. doi: 10.1002/hep.510240549

Capurro M, Wanless IR, Sherman M, Deboer G, Shi W, Miyoshi E, Filmus J (2003) Glypican-3: a novel serum and histochemical marker for hepatocellular carcinoma. Gastroenterology 125: 89-97. doi: http://dx.doi.org/10.1016/S0016-5085(03)00689-9

Capurro MI, Xiang YY, Lobe C, Filmus J (2005) Glypican-3 promotes the growth of hepatocellular carcinoma by stimulating canonical Wnt signaling. Cancer Res 65: 6245-6254. doi: 10.1158/0008-5472. CAN-04-424

Caruso ML, Valentini AM (1999) Overexpression of p53 in a large series of patients with hepatocellular carcinoma: a clinicopatho- logical correlation. Anticancer Res 19: 3853-3856. doi: 10.1002/ hep.1840160511

Chan KL, Guan XY, Ng IO (2004) High-throughput tissue microarray analysis of c-myc activation inchronic liver diseases and hepatocellular carcinoma. Hum Pathol 35: 1324-1331. doi: 10.1016/j.humpath.2004.06.012

Chang YF, Chi CW, Wang JJ (2006) Reactive oxygen species production is involved in quercetin-induced apoptosis in human hepatoma cells. Nutrition and Cancer 55: 201-209. doi: 10.1207/ s15327914nc5502_12

Chao JC, Chu CC (2004) Effects of Ginkgo biloba extract on cell proliferation and cytotoxicity in human hepatocellular carcinoma cells. World J Gastroenterol 10: 37-41. doi: 10.3748/wjg.v10.i1.37

Chen G, Wang Y, Garate M, Zhou J, Li G (2010) The tumor suppressor ING3 is degraded by SCF (Skp2)-mediated ubiquitin-proteasome system. Oncogene 29: 1498-1508. doi: 10.1038/onc.2009.424

Cohen GM (1997) Caspases: the executioners of apoptosis. Biochem J 326: $1-16$

Datta J, Kutay H, Nasser M.W, Nuovo GJ, Wang B, Majumder S, Liu CG, Volinia S, Croce CM, Schmittgen TD, Ghoshal K, Jacob ST (2008) Methylation mediated silencing of MicroRNA-1 gene and its role in hepatocellular carcinogenesis. Cancer Res 68: 5049-5058. doi: 10.1158/0008-5472.CAN-07-6655

Drury G, Wallington A (1980) Carleton's histological techniques. Oxford University Press: 403-406

El-Sayyad HI, Iasmail MF, Shalaby FM, Abou-El Magd RF, Gaur RL, Fernando A, Raj MH, Ouhtit A (2009) Histopathological effects of cisplatin, doxorubicin and 5-flurouracil (5-Fu) on the liver of male albino rats. Int J Biol Sci 5: 466-473. doi:10.7150/ijbs.5.466

El-Zayadi AR, Badran HM, Barakat EM, Attia MD, Shawky S, Mohamed MK, Selim O, Saeid A (2005) Hepatocellular carcinoma in Egypt: a single center study over a decade. World J Gastroenterol 11: 5193-5198

Eshak MG, Ghaly IS, Khalil WKB, Farag IM, Ghanem KZ (2010) Genetic alterations induced by toxic effect of thermally oxidized oil and protective role of tomatoes and carrots in mice. JAm Sci $\mathbf{6}$ : 175-188. doi:10.7537/marsjas060410.2

Faber E (1994) Programmed cell death: necrosis versus apoptosis. Mod. Pathol 7: 605-609

Farazi PA, De Pinho RA (2006) Hepatocellular carcinoma pathogenesis: from genes to environment. Nat Rev Cancer 6: 674-687. doi: $10.1038 /$ nrc193

Filmus J, Capurro M (2008) The role of glypican-3 in the regulation of body size and cancer. Cell Cycle 7: 2787-2790. doi: 10.4161/ cc.7.18.6672

Friesen C, Fulda S, Debatin KM (1999) Cytotoxic drugs and the CD95 pathway. Leukemia 13: 1854-1858. doi: 10.1038/sj.leu.2401333

Fuke H, Shiraki K, Sugimoto K, Tanaka J, Beppu T, Yoneda K, Yamamoto N, Ito K, Masuya M, Takei Y (2007) Jak inhibitor induces S phase cell-cycle arrest and augments TRAIL-induced apoptosis in human hepatocellular carcinoma cells. Biochem Biophys Res Commun 363: 738-744. doi: 10.1016/j.bbrc.2007.09.049

Genoux E, Nicolle E, Boumendjel A (2011) Flavonoids as anticancer agents: recent progress and state of the art?. Current Organic Chemistry 15: 2608-2615. doi: 10.2174/138527211796367363

Gupta C, Vikram A, Tripathi DN, Ramarao P, Jena GB (2010) Antioxidant and antimutagenic effect of quercetin against DEN induced hepatotoxicity in rat. Phytother Res 24: 119-128. doi: 10.1002/ ptr. 2883

Harring TR, Kuten DA, Nguyen NT, Goss JA, O’Mahony CA (2011) Orthotopic liver transplantation in patients with mixed hepatocellular carcinoma - cholangiocarcinoma. J Transplant Technol Res 1: 104. doi: 10.4172/2161-0991.1000104

He TC, Sparks AB, Rago C, Hermeking H, Zawel L, da Costa LT, Morin PJ, Vogelstein B, Kinzler KW (1998) Identification of cMYC as a target of the APC pathway. Science 281: 1509-1512. doi: 10.1126/science.281.5382.1509

Herrera B, Fernandez M, Alvarez A, Roncero C, Benito M, Gil J, Fabregat I (2001) Activation of caspases occurs downstream from radical oxygen species production, Bcl-xL downregulation, and early cytochrome $\mathrm{C}$ release in apoptosis induced by transforming growth factor beta in rat fetal hepatocytes. Hepatology 34: 548-556. doi:10.1053/jhep.2001.27447

Jose K, Kuttan R, Bhattacharya K (1998) Effect of Emblica officinalis extract on hepatocarcinogenesis and carcinogen metabolism. J Clin Biochem Nutr 25: 31-39. doi: 10.3164/jcbn.25.31

Karimov KHY, Inoyatova FKH, Mukhamedova MT (2003) Changes in some indices of the synthesis of nitric oxide during the early stages of hepatocarcinogenesis. Exp Toxicol Pathol 55: 17-19. doi: http:// dx.doi.org/10.1078/0940-2993-00267

Kawakami K, Enokida H, Chiyomaru T, Tatarano S, Yoshino H, Kagara I, Gotanda T, Tachiwada T, Nishiyama K, Nohata N, Seki N, Nakagawa M (2012) The functional significance of miR-1 and miR-133a in renal cell carcinoma. Eur J Cancer 48: 827-836. doi: 10.1016/j.ejca.2011.06.030 
Kim TH, Zhao Y, Barber MJ, Kuharsky DK, Yin XM (2000) Bid-induced cytochrome c release is mediated by a pathway independent of mitochondrial permeability transition pore and Bax. J Biol Chem 275: 39474-39481. doi: 10.1074/jbc.M003370200

Koon HB, Ippolito GC, Banham AH, Tucker PW (2007) Foxp-1: a potential therapeutic target in cancer. Expert Opin Ther Targets 11: 955-965. doi: 10.1517/14728222.11.7.955

Lazarevich NL (2000) Review: molecular mechanisms of alpha-fetoprotein gene expression. Biochemistry (Moscow) 65: 117-133

Lee WJ, Shim JY, Zhu BT (2005) Mechanisms for the inhibition of DNA methyltransferases by tea catechins and bioflavonoids. Mol Pharmacol 68: 1018-1030. doi: 10.1124/mol.104.008367

Lehman EM, Soliman AS, Ismail K, Hablas A, Seifeldin IA, Ramadan M, El-Hamzawy H, Shoushtari CS, Wilson ML (2008) Patterns of hepatocellular carcinoma incidence in Egypt from a populationbased Cancer registry. Hepatol Res 38: 465-473. doi: 10.1111/j.1872034X.2007.00299.x

Li L, Jin R, Zhang X, Lv F, Liu L, Liu D, Liu K, Li N, Chen D (2012a) Oncogenic activation of glypican-3 by c-Myc in human hepatocellular carcinoma. Hepatology 56: 1380-1390. doi: 10.1002/ hep. 25891

Li D, Yang P, Li H, Cheng P, Zhang L, Wei D, Su X, Peng J, Gao H, Tan Y, Zhao Z, Li Y, Qi Z, Rui Y, Zhang T (2012b) MicroRNA-1 inhibits proliferation of hepatocarcinoma cells by targeting endothelin-1. Life Sci 91: 440-447. doi: 10.1016/j.lfs.2012.08.015

Liao DJ, Blanck A, Eneroth P, Gustafsson JA, Hällström IP (2001) Diethylnitrosamine causes pituitary damage, disturbs hormone levels, and reduces sexual dimorphism of certain liver functions in the rat. Environ Health Perspect 109: 943-947

Lu M, Chen F, Wang Q, Wang K, Pan Q, Zhang X (2012) Downregulation of inhibitor of growth 3 is correlated with tumorigenesis and progression of hepatocellular carcinoma. Oncology Letters 4: 4752. doi: 10.3892/ol.2012.68

Lubgan D, Marczak A, Walczak M, Distel L, Jóźwiak Z (2006) Pharmacological mechanisms of doxorubicin activity (DOX) - current state of knowledge. Przegl Lek 63: 782-788

Luo J, Shah S, Riabowol K, Mains PE (2009) The Caenorhabditis elegans ING-3 gene regulates ionizing radiation-induced germ-cell apoptosis in a p53-associated pathway. Genetics 181: 473-482. doi: 10.1534/genetics.107.080515

Macnab GM, Urbanowicz JM, Kew, MC (1978) Carcinoembryonic antigen in hepatocellular cancer. $\mathrm{Br}$ J Cancer 38: 51-54. doi: 10.1038/ bjc. 1978.162

Marcocci L, Packer L, Droy-Lefaix MT, Sekaki A, Gardès-Albert M (1994) Antioxidant action of Ginkgo biloba extract EGb 761. Methods Enzymol 234: 462-475

Middleton E, Jr, Kandaswami C, Theoharidis TC (2000) The impact of plant flavonoids on mammalian biology: implications for immunity, inflammation and cancer. Pharmacol Rev 52: 673-751. doi: 10.1007/978-1-4899-2911-2_15

Motalleb G, Hanachi P, Fauziah O, Asmah R (2008) Effect of Berberis vulgaris fruit extract on alpha-fetoprotein gene expression and chemical carcinogen metabolizing enzymes activities in hepatocarcinogenesis rats. Iranian J Cancer Prevention 1: 33-44

Nagashima M, Shiseki M, Pedeux RM, Okamura S, Kitahama-Shiseki M, Miura K, Yokota J, Harris CC (2003) A novel PHD-finger motif protein, p47ING3, modulates p53-mediated transcription, cell cycle control and apoptosis. Oncogene 22: 343-350. doi:10.1038/ sj.onc. 1206115

Nakamura T, Ueda Y, JuanY, Katsuda S, Takahashi H, Koh E (2000) Fas-mediated apoptosis in adriamycin induced cardiomyopathy in rats: in vivo study. Circulation 102: 572-578. doi: http://dx.doi. org/10.1161/01.CIR.102.5.572

Ogdene SK, Lee KC, Wernke-Dollries K, Stratton SA, Aronow B, Barton MC (2001) p53 targets chromatin structure alteration to repress alpha-fetoprotein gene expression. J Biol Chem 276: 42057-42062. doi: 10.1074/ibc.C100381200

Oka H, Saito A, Ito K, Kumada T, Satomura S, Kasugai H, Osaki Y, Seki T, Kudo M, Tanaka M (2001) Multicenter prospective analysis of newly diagnosed hepatocellular carcinoma with respect to the percentage of Lens culinaris agglutinin-reactive alpha-fetoprotein. J Gastroenterol Hepatol 16: 1378-1383. doi: 10.1046/j.14401746.2001.02643x

Pan G, Ni J, Wei YF, Yu G, Gentz R, Dixit VM (1997) An antagonist decoy receptor and a death domain-containing receptor for TRAIL. Science 277: 815. doi: 10.1126/science.277.5327.815

Park CH, Chang JY, Hahm ER, Park S, Kim HK, Yang CH (2005) Quercetin, a potent inhibitor against b-catenin/Tcf signaling in SW480 colon cancer cells. Biochem Biophys Res Commun 328: 227-234. doi: 10.1016/j.bbrc.2004.12.151

Pratt WB, Ruddon RW, Ensminger WD, Maybaum J (1994) The anticancer drugs. Oxford University Press. New York

Premalatha B, Sachdanandam P (1999) Effects of semecarpus anacardium nut milk extract on rat serum alpha-fetoprotein level in aflatoxin B1-mediated hepatocellular carcinoma. Fitoterapia 70: 279-283. doi: 10.1016/S0367-326X(99)00043-X
Puttalingamma V (2015) Ginkgo biloba living fossil, wonderful medicinal plant - a review. Int J Adv Res 3: 506-511

Ramakrishnan G, Jagan S, Kamaraj S, Anandakumar P, Devaki T (2009) Silymarin attenuated mast cell recruitment thereby decreased the expressions of matrix metalloproteinases- 2 and 9 in rat liver carcinogenesis. Invest New Drugs 27: 233-240. doi: 10.1007/s10637-0089163-y

Reid JF, Sokolova V, Zoni E, Lampis A, Pizzamiglio S, Bertan C, Zanutto S, Perrone F, Camerini T, Gallino G, Verderio P, Leo E, Pilotti S, Gariboldi M, Pierotti MA (2012) MicroRNA profiling in colorectal cancer highlights miR-1 involvement in MET-dependent proliferation. Molecular Cancer Res 10: 504-515. doi: 10.1158/15417786.MCR-11-0342

Russo M, Spagnuolo C, Tedesco I, Bilotto S, Russo GL (2012) The flavonoid quercetin in disease prevention and therapy: facts and fancies. Biochemical Pharmacology 83: 6-15. doi: 10.1016/j.bcp.2011.08.010 Saad SY, Najja TA, Al-Rikabi AC (2001) The preventive role of deferoxamine against acute doxorubicin-induced cardiac, renal and hepatic toxicity in rats. Pharmacol Res 43: 211-218. doi: 10.1006/ phrs.2000.0769

Sadiknah NAH, EL-Maraghy SA, Ismail MF (2008) Diethylnitrosamine induced hepatocarcino-genesis in rats: possible chemoprevention by blueberries. African J Bioch Res 2: 081-087

Sagar SM, Yance D, Wong RK (2006) Natural health products that inhibit angiogenesis: a potential source for investigational new agents to treat cancer-Part 1. Curr Oncol 13: 14-26

Sapisochin G, Charco R (2011) Salvage liver transplantation for HCC: an old story without consensus? I Transplant Technol Res 1: 06. doi: 10.4172/2161-0991.1000106e

Scherer E, Emmelot P (1975) Kinetics of induction and growth of precancerous liver cell foci, and liver tumour formation by diethylnitrosamine in the rat. Eur J Cancer 11: 689-696. doi: http://dx.doi. org/10.1016/0014-2964(75)90042-0

Shu W, Lu MM, Zhang Y, Tucker PW, Zhou D, Morrisey EE (2007) Foxp2 and Foxp1 cooperatively regulate lung and esophagus development. Development 134: 1991-2000. doi: 10.1242/dev.02846

Sivaramakrishnan V, Pnm S, Vrp K, Devaraj SN (2008). Attenuation of N-nitrosodiethylamine-induced hepatocellular carcinoma by a novel flavonol-Morin. Chem Biol Interact 171: 79-88. doi: 10.1016/j. cbi.2007.09.003

Suzuki MI, Sugimoto K, Tanaka J, Tameda M, Inagaki Y, Kusagawa S, Nojiri K, Beppu T, Yoneda K, Yamamoto N, Ito M, Yoneda M, Uchida K, Takase K, Shiraki K (2010) Up-regulation of glypican-3 in human hepatocellular carcinoma. Anticancer Res 30: 5055-5061

Tanigawa S, Fujii M, Hou DX (2008) Stabilization of p53 is involved in quercetin-induced cell cycle arrest and apoptosis in HepG2 cells. Biosci Biotechnol Biochem 72: 797-804. doi: 10.1271/bbb.70680

Thomas P, Hems DA (1975) The hepatic clearance of circulating native and asialo carcinoembryonic antigen by the rat. Biochem Biophys Res Comm 67: 1205-1209

Van Beek TA (2002) Chemical analysis of Ginkgo biloba leaves and extracts. I Chromatography A 967: 21-55. doi: 10.1016/j.chroma.2009.01.013

Verna L, Whysner J, Williams GM (1996) N-Nitrodiethylamine mechanistic data and risk assessment: bioactivation, DNA-adduct formation, mutagenicity and tumor initiation. Pharmacol Ther 71: 57-81. doi: 10.1016/0163-7258(96)00062-9.

Wang Y, Li G (2006) ING3 promotes UV-induced apoptosis via Fas/ caspase-8 pathway in melanoma cells. J Biol Chem 281: 11887-11893. doi: 10.1074/jbc.M511309200

Wang Y, Shen Y (2013) Unresectable hepatocellular carcinoma treated with transarterial chemoembolization: clinical data from a single teaching hospital. Int J Clin Exp Med 6: 367-371. doi: http://dx.doi. org/null

Yang CS, Fang M, Lambert JD, Yan P, Huang TH (2008) Reversal of hypermethylation and reactivation of genes by dietary polyphenolic compounds. Nutr Rev 66: 18-20. doi: 10.1111/j.17534887.2008.00059.x

Yang HY, Liu HL, Tian LT, Song RP, Song X, Yin DL, Liang YJ, Qu LD, Jiang HC, Liu JR, Liu LX (2012) Expression and prognostic value of ING3 in human primary hepatocellular carcinoma. Experimental Biology and Medicine 237: 352-361. doi: 10.1258/ ebm.2011.011346

Yokochi T, Robertson KD (2004) Doxorubicin inhibits DNMT1, resulting in conditional apoptosis. Mol Pharmacol 66: 1415-1420. doi: 10.1124/mol.104.002634

Zhang XL, Yu H, Xiong YY, Ma ST, Zhao L, She SF (2013) Resveratrol down-regulates myosin light chain kinase, induces apoptosis and inhibits diethylnitrosamine-induced liver tumorigenesis in rats. Int J Mol Sci 14: 1940-1951. doi: 10.3390/ijms14011940

Zhang Y, Zhang S, Wang X, Liu J, Yang L, He S, Chen L, Huang J (2012) Prognostic significance of Foxp-1 as an oncogene in hepatocellular carcinoma. I Clin Pathol 65: 528-533. doi: 10.1136/jclinpath-2011-200547 